\title{
Epigenetic suppression of liver $X$ receptor $\beta$ in anterior cingulate cortex by HDAC5 drives CFA-induced chronic inflammatory pain
}

Yu-Jiao Li $i^{1,2 \dagger}$, Kun Zhang ${ }^{1,2 \dagger}$, Ting Sun ${ }^{1 \dagger}$, Jian Wang ${ }^{3}$, Yan-Yan Guo ${ }^{1}$, Le Yang ${ }^{1}$, Qi Yang ${ }^{1}$, Yan-Jiao Li ${ }^{2,4}$, Shui-Bing Liu', Ming-Gao Zhao ${ }^{1,2^{*}}$ and Yu-Mei Wu ${ }^{2^{*}}$ (i)

\begin{abstract}
Background: Liver $X$ receptors (LXRs), including $L X R a$ and $L X R \beta$, are key regulators of transcriptional programs for both cholesterol homeostasis and inflammation in the brain. Here, the modes of action of LXRs and the epigenetic mechanisms regulating LXRß expression in anterior cingulate cortex (ACC) of chronic inflammatory pain (CIP) are investigated.

Methods: The deficit of LXR isoform and analgesic effect of LXR activation by GW3965 were evaluated using the mouse model of CIP induced by hindpaw injection of complete Freund's adjuvant (CFA). The mechanisms involved in GW-mediated analgesic effects were analyzed with immunohistochemical methods, ELISA, co-

immunoprecipitation (Co-IP), Western blot, and electrophysiological recording. The epigenetic regulation of LXR expression was investigated by chromatin immunoprecipitation, quantitative real-time PCR, and sequencing.

Results: We revealed that CFA insult led to LXRB reduction in ACC, which was associated with upregulated expression of histone deacetylase 5 (HDAC5), and knockdown of LXRß by shRNA led to thermal hyperalgesia. Co-IP showed that LXR $\beta$ interacted with NF-KB p65 physically. LXR $\beta$ activation by GW3965 exerted analgesic effects by inhibiting the nuclear translocation of NF-KB , reducing the phosphorylation of mitogen-activated protein kinases (MAPKS) in ACC, and decreasing the promoted input-output and enhanced mEPSC frequency in ACC neurons after CFA exposure. In vitro experiments confirmed that HDAC5 triggered histone deacetylation on the promoter region of $L x r \beta$, resulting in downregulation of $L x r \beta$ transcription.

Conclusion: These findings highlight an epigenetic mechanism underlying LXR 3 deficits linked to CIP, and LXR $\beta$ activation may represent a potential novel target for the treatment of CIP with an alteration in inflammation responses and synaptic transmission in ACC.
\end{abstract}

Keywords: Chronic inflammatory pain, Anterior cingulate cortex, Liver X receptors, Histone modification, Neuroinflammation, Neurotransmission

\footnotetext{
* Correspondence: minggao@fmmu.edu.cn; yumeiwu@fmmu.edu.cn

${ }^{\dagger}$ YUu-Jiao Li, Kun Zhang, and Ting Sun contributed equally to this study.

'Department of Pharmacy, Precision Pharmacy \& Drug Development Center,

The Second Affiliated Hospital, Fourth Military Medical University, Xi'an

710038, Shaanxi Province, People's Republic of China

${ }^{2}$ Department of Pharmacology, School of Pharmacy, Fourth Military Medical

University, Xi'an 710032, Shaanxi Province, People's Republic of China

Full list of author information is available at the end of the article
}

(c) The Author(s). 2019 Open Access This article is distributed under the terms of the Creative Commons Attribution 4.0 International License (http://creativecommons.org/licenses/by/4.0/), which permits unrestricted use, distribution, and reproduction in any medium, provided you give appropriate credit to the original author(s) and the source, provide a link to the Creative Commons license, and indicate if changes were made. The Creative Commons Public Domain Dedication waiver (http://creativecommons.org/publicdomain/zero/1.0/) applies to the data made available in this article, unless otherwise stated. 


\section{Background}

Chronic pain is defined as a neuroepigenetic disorder caused by persistent tissue inflammation or nerve injury under various pathological conditions, which is accompanied by lasting, multifaceted maladaptations ranging from gene modulation to synaptic dysfunction and emotional disorders [1, 2]. Inflammation, tissue injury, and/or nerve injury-induced changes of gene expression in sensory neurons from the dorsal root ganglion, dorsal horn of spinal cord, and pain-associated brain regions are thought to participate in chronic pain genesis; however, how these changes occur is still elusive and efforts have been made to look for the genetic mechanisms involved in the regulation of gene expression. Epigenetic modifications, including DNA methylation, histone modifications, and microRNAs, strongly govern gene expression, potentially for long periods over years or even generations, and have been associated with the induction of pain hypersensitivity under chronic pain conditions [3].

Studies demonstrated that many genes undergo expression changes at mRNA and protein levels in tissues or cells of pain circuitry during the development or maintenance of persistent pain [3]. Liver $X$ receptors (LXRs), including LXR $\alpha / \mathrm{NR} 1 \mathrm{~h} 3$ and LXR $\beta / \mathrm{NR} 1 \mathrm{~h} 2$, belong to the nuclear receptor superfamily of transcription factors [4]. LXRs have emerged as important regulators controlling cellular and whole-body cholesterol homeostasis [5]. Given the complexity of metabolic regulation by LXRs, it has been difficult to define their roles in normal function or disease states. LXR $\alpha$ is expressed predominantly in organs of lipid metabolism, whereas LXR $\beta$ is expressed ubiquitously in most of the physical system and plays crucial roles in the immune system and central nervous system (CNS). LXR $\alpha$ knockout did not cause fundamental developmental defects in mice, whereas LXR $\beta$ deletion led to impaired cerebral cortex lamination [6], neurodegeneration in substantia nigra [7], anxiety, and impaired behavior response [8]. Furthermore, LXR $\beta$ was also expressed in the spinal cord, and male $\mathrm{LXR}^{-/-}$mice suffered from adult-onset motor neuron degeneration [9], whereas LXR $\beta$ activation by T0901317 protected the spinal cord from injury [10]. Both T0901317 and GW3965 (GW) [11] are synthetic ligands for LXRs, and GW is an LXR full agonist for both LXR $\alpha$ and LXR $\beta$ isoforms and can readily cross the blood-brain barrier to exert its specific actions in the brain [12]. Notably, the role of LXRs in chronic pain remains largely unknown.

Central sensitization plays a key role in the process of chronic pain, which is associated with the activation of a distributed group of structures, including the somatosensory cortex, the insular cortex, and the anterior cingulate cortex (ACC) $[13,14]$. ACC attracts more and more attention in pain research which plays key roles in pain modulation, learning, memory, and attention [15, 16]. Our previous work revealed a significant enhancement in the probability of neurotransmitter release in ACC synapses from mice with chronic pain [17]. More and more evidence linked central sensitization to abnormal gene expression within the cells processing nociceptive signaling in CNS $[3,18]$.

In this study, we investigated whether dysfunction of LXR $\beta$ led to hyperalgesia and the epigenetic regulation mechanisms involved. Here, we demonstrated the downregulation of LXR $\beta$ not LXR $\alpha$ in ACC of chronic inflammatory pain (CIP) mice, and knockdown of LXR $\beta$ by short hairpin RNA (shRNA) led to thermal hyperalgesia, while activation of LXR $\beta$ by GW exerted analgesic effects through both anti-inflammation and correction in synaptic transmission in ACC. Chromatin immunoprecipitation (ChIP) analysis showed that histone deacetylase 5 (HDAC5) triggered histone deacetylation on the promoter region of $L x r \beta$, resulting in the reduction of $L x r \beta$ transcription in cultured cortical neurons. Taken together, these findings highlight an epigenetic mechanism underlying LXR $\beta$ deficits linked to CIP, revealing potentially targetable receptor for clinical intervention in CIP.

\section{Materials and methods \\ Animals}

Adult male C57BL/6 mice aged 6-8 weeks were purchased from the Fourth Military Medical University Experimental Animal Center (Xi'an, China). Animals were housed in groups of five under standard laboratory conditions $\left(24 \pm 2{ }^{\circ} \mathrm{C}, 12\right.$-h light/dark cycle, food and water ad libitum). All behavioral tests were performed during the light period on the designated day of experiment. All experimental procedures were approved by the Fourth Military Medical University Animal Care and Use Committee. Every effort was made to minimize the number of animals used and their suffering.

\section{Experimental designs and GW3965 treatment}

The model of CIP was established by hindpaw CFA injection according to previous studies [19-21]. Either GW (1 and $10 \mathrm{mg} / \mathrm{kg}$, Selleckchem, Shanghai, China) or $0.9 \%$ saline (vehicle, $0.2 \mathrm{ml}$ ) was administered intraperitoneally (i.p) immediately after CFA insult (10 $\mu \mathrm{l}, 50 \%$ in saline) for another consecutive 14 days. All the samples for Western blot and immunohistochemistry were collected from the ipsilateral ACC of CFA injection into the hindpaw.

\section{Nociceptive behavioral tests}

Mechanical allodynia was assessed by von Frey filaments [22], and thermal hyperalgesia was evaluated via a plantar analgesia device (BME410A, China), which is 
measured as paw withdrawal threshold according to previous research [23].

\section{shRNA lentivirus construction and transfection}

To knock down endogenous LXRs, shRNA-coding plasmids against LXR $\alpha$ (NM_013839.4) and LXR $\beta$ (NM_009473.3) were designed according to validated shRNA sequences [24]. Lentivirus (pGLV-U6-GFP)-encoding shRNAs for LXR $\alpha$ and LXR $\beta$ were prepared by GenePharma (Shanghai, China). The sequence of shRNA for LXR $\alpha(\operatorname{sh} L X R \alpha)$ was 5'-TGCCTGATGTTTCTCCTGAT-3', and that of shRNA for LXR $\beta$ (shLXR $\beta$ ) was 5'-GGATTCAGAAGCAGCAACAT-3'. Negative shRNA for LXRs (shNC) served as a lentivirus infection control.

\section{Stereotaxic surgery and microinjections}

Mice were anesthetized with a mixture of ketamine $(30 \mathrm{mg} /$ $\mathrm{ml})$ and xylazine $(3 \mathrm{mg} / \mathrm{ml})$ and were mounted on a stereotaxic apparatus (RWD68001, Shenzhen Ruiwode Life Science, China). An attenuated glass electrode (approximately $10 \mu \mathrm{m}$ in diameter) was implanted bilaterally into the ACC ( $+1.0 \mathrm{~mm}$ anteroposterior, $\pm 0.3 \mathrm{~mm}$ lateral to the midline, and $-1.5 \mathrm{~mm}$ dorsoventral). The mice received lentiviral shLXR $\alpha$ or shLXR $\beta\left(2 \mu \mathrm{l}, 1 \times 10^{9} \mathrm{gc} / \mathrm{ml}\right)$ bilaterally at $0.25 \mu \mathrm{l} / \mathrm{min}$ driven by an infusion pump (Harvard Apparatus, MA). shNC served as an infection control. The CIP model was set up 14 days after shRNA infection, and mice were treated as before.

\section{Locomotor activity tests}

Behavioral tests were carried out 2 weeks after lentivirus injection. Locomotor activity was conducted using the open-field and rotarod test as described previously [25].

\section{Western blot analysis}

Samples from mice ACC were collected. Total proteins were lysed by M-PER Protein Extraction Buffer, and nuclear proteins of ACC were extracted with nuclear extraction kit (Thermo) according to the manufacturer's instructions. Protein concentrations were determined using a BCA Kit. Equal amounts of protein aliquots were used for Western blot analysis to check the expression levels of LXR $\alpha$, LXR $\beta$, p50, p65, HDAC2, HDAC5, Iba-1

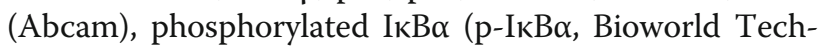
nology), phosphorylated extracellular regulated protein kinases (p-ERKs), ERK, phosphorylated p38 (p-p38), p38, phosphorylated c-Jun N-terminal kinase (p-JNK), JNK, GFAP (Cell Signaling Technology), AcH3 and AcH4 (Millipore), Histone H3, Histone H4, $\beta$-tubulin III (Proteintech), and $\beta$-actin (Sigma-Aldrich) served as a loading control.

\section{Immunohistochemistry}

Frozen sections were fixed in acetone for $10-15 \mathrm{~min}$ and incubated in $3 \% \mathrm{H}_{2} \mathrm{O}_{2}$ in PBS for $15 \mathrm{~min}$ to quench endogenous peroxidase at room temperature. To block nonspecific binding, sections were blocked in 3\% BSA for $10 \mathrm{~min}$, after which a biotin blocking system (Dako) was used to block endogenous biotin. Sections were then incubated with rabbit anti-LXR $\beta$ in $1 \%$ BSA overnight at room temperature. BSA replaced the primary antibodies in the negative controls. After washing, sections were incubated with the corresponding secondary antibodies using a rabbit HRP-polymer kit (P0203; Beyotime) for $15-20 \mathrm{~min}$ at room temperature, followed by $\mathrm{DAB}$ as a chromogen. Total number of LXR $\beta$-positive cells in ACC was counted using the optical fractionator method of unbiased stereology. Briefly, the optical dissector had a size of $20 \mu \mathrm{m} \times 20 \mu \mathrm{m}$ in the $X$ - and $Y$-axis from ACC of the section. Dissectors were positioned every $50 \mu \mathrm{m}$ in the $X$ - and $Y$-axis. The sampled region for each ACC subfield was demarcated, and DAB LXR $\beta$-positive cells were counted. The estimated number of LXR $\beta$ positive cells in each field was divided by the area of the region of interest to obtain the cellular density expressed in cells per $0.04 \mathrm{~mm}^{2}$.

\section{Immunofluorescence}

Animals were intracardially perfused with $0.9 \%$ saline and $4 \%$ PFA (wt/vol). Floating sections containing ACC $(30 \mu \mathrm{m})$ were collected and subjected to immunohistochemistry using anti-LXR $\alpha$, anti-LXR $\beta$, anti-p65, anti- $\beta$ tubulin III, anti-Iba-1, anti-GFAP, anti-NeuN, anti-CAMK II $\alpha$, and anti-GAD67. Nuclei were counterstained with Hoechst 33258. Fluorescent signals were photographed and analyzed using confocal fluorescence microscopy (Olympus, Japan).

\section{Enzyme-linked immunosorbent assay}

The levels of tumor necrosis factor- $\alpha$ (TNF- $\alpha$ ), apolipoprotein $\mathrm{E}$ (ApoE) and ATP-binding cassette transporter (ABCA1) in blood and ACC were determined after the intraplantar injection of CFA with or without GW administration via enzyme-linked immunosorbent assay (ELISA) according to the manufacturer's instructions.

\section{Whole-cell patch-clamp recording}

Coronal slices $(300 \mu \mathrm{m})$ containing ACC were prepared as described previously [17]. Slices were transferred to a recovery chamber with oxygenated $\left(95 \% \mathrm{O}_{2}\right.$ and $5 \%$ $\mathrm{CO}_{2}$ ) artificial cerebrospinal fluid containing the following (in $\mathrm{mM}$ ): $124 \mathrm{NaCl}, 2.5 \mathrm{KCl}, 2 \mathrm{CaCl}_{2}, 2 \mathrm{MgSO}_{4}, 25$ $\mathrm{NaHCO}_{3}, 1 \mathrm{NaH}_{2} \mathrm{PO}_{4}$, and 10 glucose, for at least $1 \mathrm{~h}$ at room temperature. Excitatory postsynaptic currents (EPSCs) were recorded from layer II to III neurons of ACC with an Axopatch 200B amplifier (Axon 
Instruments, $\mathrm{CA}$ ), and the stimulations were delivered in layer V of ACC. $\alpha$-Amino-3-hydroxy-5-methyl-4-isoxazolepropionic acid (AMPA) receptor-mediated EPSCs were induced through repetitive stimulations at $0.02 \mathrm{~Hz}$, and neurons were voltage clamped at $-70 \mathrm{mV}$. The recording pipettes (3-5 M $\Omega$ ) were filled with solution containing the following (in $\mathrm{mM}$ ): $145 \mathrm{~K}$-gluconate, $5 \mathrm{NaCl}$, $1 \mathrm{MgCl}_{2}, 0.2$ EGTA, 10 HEPES, $2 \mathrm{Mg}$-ATP, and $0.1 \mathrm{Na}_{3}$ GTP, adjusted to $\mathrm{pH} 7.2$ with $\mathrm{KOH}$. For miniature EPSC (mEPSC) recording, TTX $(0.5 \mu \mathrm{M})$ was added in the perfusion solution, and picrotoxin $(100 \mu \mathrm{M})$ was always present to block $\mathrm{GABA}_{\mathrm{A}}$ receptor-mediated inhibitory synaptic currents. Access resistance was $15-30 \mathrm{M} \Omega$ and monitored throughout the experiment. Data were discarded if access resistance changed more than 15\% during an experiment.

\section{Co-immunoprecipitation}

ACC was rapidly removed and washed in ice-cold PBS (0.1 $\mathrm{mM}$ ) and lysed in NP-40 lysis buffer (Beyotime). The extract was pre-incubated with protein A/G PLUS-Agarose (Thermo Fisher) and normal rabbit IgG antibodies for 30 min at $4{ }^{\circ} \mathrm{C}$. The mixture was then centrifuged at $2500 \mathrm{rpm}$ for $5 \mathrm{~min}$ at $4{ }^{\circ} \mathrm{C}$. For immunoprecipitation, equal amounts of protein were incubated with anti-p65, anti-LXR $\beta$, or rabbit IgG at $4{ }^{\circ} \mathrm{C}$ for $2 \mathrm{~h}$. Then, resuspended magnetic beads were added to each sample and incubated overnight at $4{ }^{\circ} \mathrm{C}$. Magnetic beads were washed with lysis buffer three times and resuspended in SDS sample buffer. The immunoprecipitated protein complex were separated by SDSPAGE and analyzed by immunoblotting using antibodies against p65 or LXR $\beta$.

\section{RNA extraction and quantitative real-time PCR}

Total RNA was isolated from neuron cultures using a standard method of phenol: chloroform extraction. cDNA was prepared using One Step SYBR $^{\circ}$ PrimeScript ${ }^{\mathrm{TM}}$ RT-PCR Kit [26] according to the manufacturer's instructions. Quantitative real-time PCR (qRTPCR) was performed on the SYBR ${ }^{\circ}$ Premix Ex Taq ${ }^{\mathrm{TM}}$ in a Bio-Rad CFX96TM real-time PCR detection system (Bio-Rad) with the following thermocycling conditions: denaturation at $95^{\circ} \mathrm{C}$ for $15 \mathrm{~min}$, followed by 40 cycles of denaturation at $95^{\circ} \mathrm{C}$ for $10 \mathrm{~s}$ and annealing at $55^{\circ} \mathrm{C}$ for $30 \mathrm{~s}$. Detection of the fluorescent product was carried out at the end of $95^{\circ} \mathrm{C}$ extension incubation. PCR products were subjected to a melting curve analysis, and relative expression was calculated for each gene by the $2^{-\Delta \Delta C T}$ method [27]. All qRTPCR reactions were performed in triplicate, and target gene expression was normalized to the levels of GAPDH mRNA. The primers used in this study were listed in Additional file 1: Table S1.

\section{Chromatin immunoprecipitation}

Chromatin immunoprecipitation was performed using the EZ-Magna chip $^{\mathrm{TM}} \mathrm{A} / \mathrm{G}$ Kit (Millipore, 17-10086) [28]. Neurons grown on $60 \mathrm{~mm}^{2}$ culture dishes were cross-linked with $1 \%$ formaldehyde for $10 \mathrm{~min}$ at room temperature, followed by quenching the reaction with $0.125 \mathrm{M}$ glycine. Samples were transferred to ice and washed with $1 \mathrm{ml}$ PBS. The cells were incubated for 15 min on ice with $250 \mathrm{ml}$ lysis buffer (including protease inhibitors). The lysate was sonicated to generate 200$1000 \mathrm{bp}$ chromatin fragments. The supernatants after centrifugation were divided into three samples of $50 \mu$ l. Protein concentrations from different groups were measured by BCA assay and adjusted to the same protein level. Lysate was diluted 1:10 with dilution buffer (including protease inhibitors). Anti-AcH3 antibody $(5 \mu \mathrm{l})$, anti-AcH4 antiserum $(3 \mu \mathrm{l})$ or normal mouse IgG $(1 \mu \mathrm{l})$, and protein $\mathrm{A} / \mathrm{G}$ beads $(20 \mu \mathrm{l})$ were mixed, and samples were rotated overnight at $4{ }^{\circ} \mathrm{C}$. Beads were washed with washing buffer for four times. Chromatin complexes were eluted with $100 \mu \mathrm{l}$ elution buffer (including Proteinase $\mathrm{K}$ ), and the eluate was incubated at $62{ }^{\circ} \mathrm{C}$ for $2 \mathrm{~h}$ and $95^{\circ} \mathrm{C}$ for $10 \mathrm{~min}$. DNA was purified and analyzed by qRT-PCR using primers listed in Additional file 1: Table S1. Purified DNA sequencing was carried out by GeneCreate Biological Engineering Co., Ltd [29] and analyzed using Chromas 2.

\section{Data analysis}

Results were analyzed by SPSS 19.0 and expressed as mean \pm SEM. Differences between experimental groups were assessed by two-sample (unpaired Student's) twotailed $t$ test assuming equal variance when comparing means between two groups; one-way ANOVA with least significant difference [5] test was used when comparing means between three or more groups; one-way ANOVA with Dennett's T3 test was used when data were not passed the homogeneity test. Data of multiple groups were analyzed by two-way ANOVA followed by post hoc Tukey tests. In all cases, $p<0.05$ was considered statistically significant.

\section{Results \\ Dysfunction of LXR $\beta$ in ACC was required for developmental chronic pain mouse model}

LXRs have been implicated in regulating cellular immunity and neuroinflammation, which may create a favorable microenvironment for anti-inflammation in the CNS. However, the role of LXRs in CIP is rarely reported. Immunofluorescent staining showed that LXR $\beta$ was widely expressed in ACC, whereas the expression of LXR $\alpha$ was very limited in ACC (Additional file 2: Figure S1). To determine whether LXRs signaling is required for chronic pain, complete Freund's adjuvant (CFA) were 
injected into the hindpaws of mice to induce inflammatory pain. LXR $\alpha$ had low basal expression in ACC of naive mice and was not altered after CFA injection $(p>$ 0.05 ; Fig. 1a, b), whereas LXR $\beta$ was relatively strongly expressed in ACC from healthy mice and substantially decreased in the CFA-treated mice $(p<0.001$; Fig. 1c-i). And the reduction of LXR $\beta$ expression in ACC induced by CFA insult lasted to day 14 compared with the Sham group ( $p<0.05$, CFA vs. Sham; Additional file 3: Figure S2). These data suggested that LXR $\beta$ deficit in ACC may play an important role in the occurrence and maintenance of chronic pain. To further determine the roles of different LXR subtypes in the development of CIP, the expression levels of LXR $\alpha$ or LXR $\beta$ was knocked down via lentiviral shLXR $\alpha$ or shLXR $\beta$ transfection in the bilateral ACC, respectively. shLXR infection resulted in a reduction of $\mathrm{LXR} \alpha$ protein to $52.1 \% \pm 4.5 \%$ and $\operatorname{LXR} \beta$ to $42.8 \% \pm 7.5 \%$ of shNC $(p<0.01, v s$. shNC; Fig. 1 j, k $)$. Both shLXR $\alpha$ and shNC groups presented no differences in response threshold to mechanical and thermal stimuli $(p>0.05$, vs. shNC; Fig. 1l, m). However, shLXR $\beta$ mice exhibited hyperalgesia $(p<0.05$, vs. shNC; Fig. $1 \mathrm{~m})$ but not allodynia ( $p>0.05$, vs. shNC; Fig. 11$)$. At the same time, no significant locomotor changes were observed in each group evaluated by open-field test and rotarod test after shRNA infection in ACC ( $p>0.05$, vs. shNC; Additional file 4: Figure S3). Collectively, LXR $\beta$ was involved in modulating the basal state of thermal sensitivity instead of mechanical nociception.

\section{LXRa/ $\beta$ dual agonist GW3965 inhibited the development of mechanical allodynia and thermal hyperalgesia after CFA injection in mice}

The analgesic effects of LXR activation by GW3965 (GW) [11], an LXR $\alpha / \beta$ dual agonist, were tested according to Fig. 2a. CFA injection induced sensory hypersensitivity which was manifested as mechanical allodynia and thermal hyperalgesia $(p<0.001$, CFA vs. Sham; Fig. $2 \mathrm{~b}, \mathrm{~d})$. GW administration $(10 \mathrm{mg} / \mathrm{kg}$, i.p) once per day immediately after CFA injection gradually relieved mechanical allodynia $(p<0.01$, CFA $+\mathrm{GW}$ vs. CFA; Fig. 2b) and thermal hyperalgesia $(p<0.05$, CFA + GW vs. CFA; Fig. 2d). However, GW showed a weak analgesic effect at lower dose of $1 \mathrm{mg} / \mathrm{kg}$ compared with that of $10 \mathrm{mg} / \mathrm{kg}$. As a control, no pain behavior was observed in the contralateral hindpaw ( $p>0.05$; Fig. 2c, e). These results indicated that LXR activation by GW prevented the development of chronic pain.

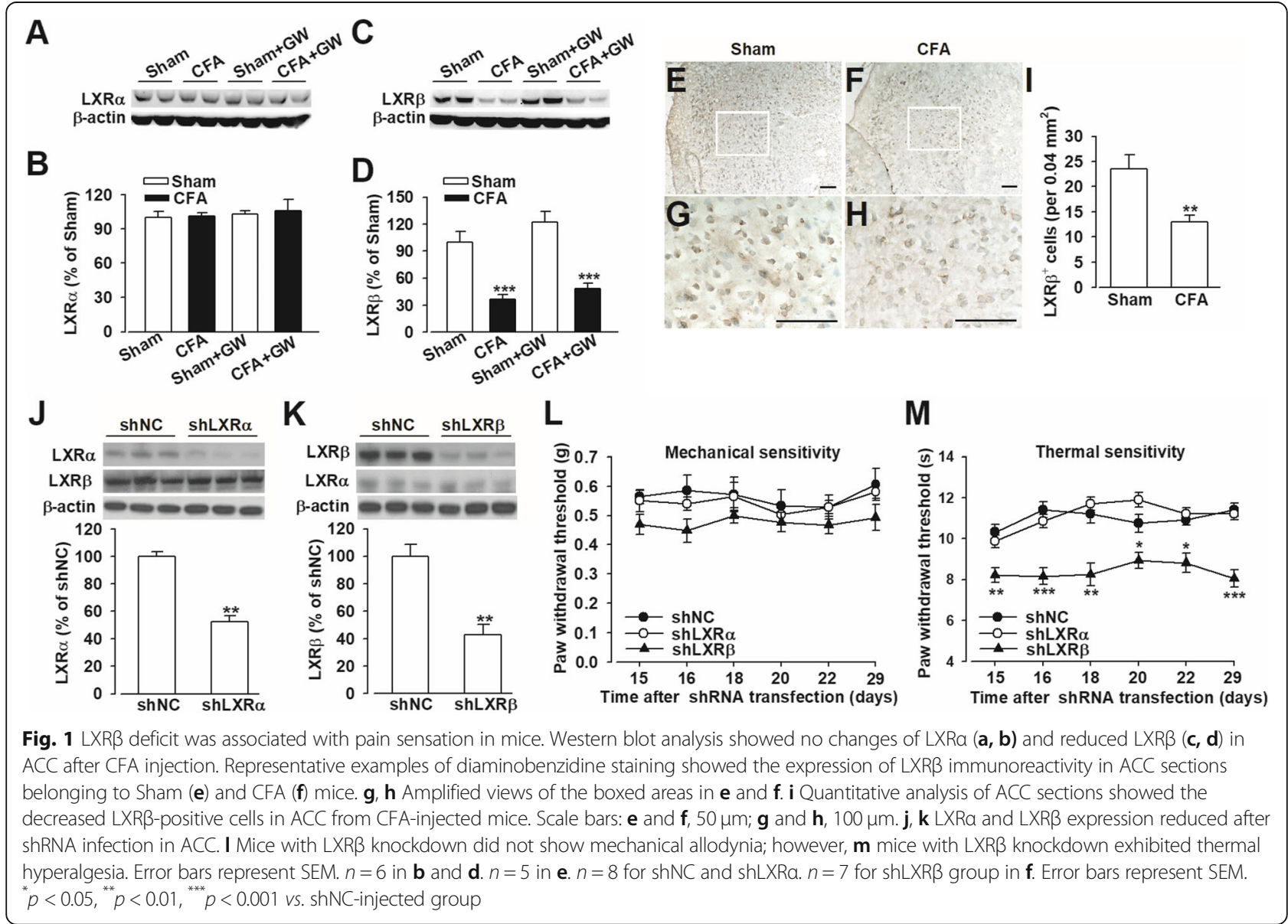




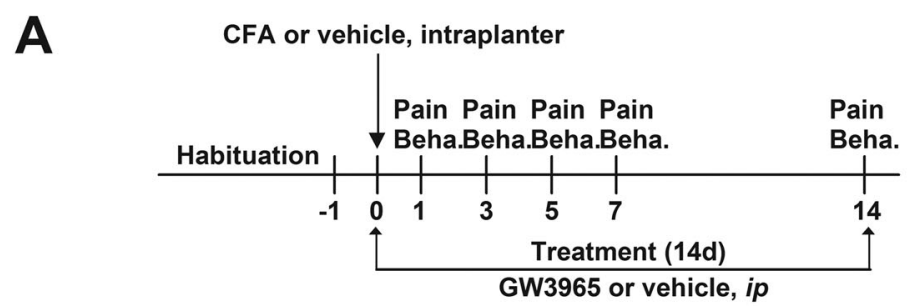

B

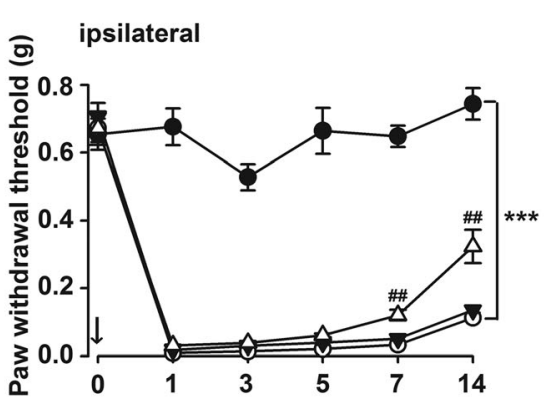

D

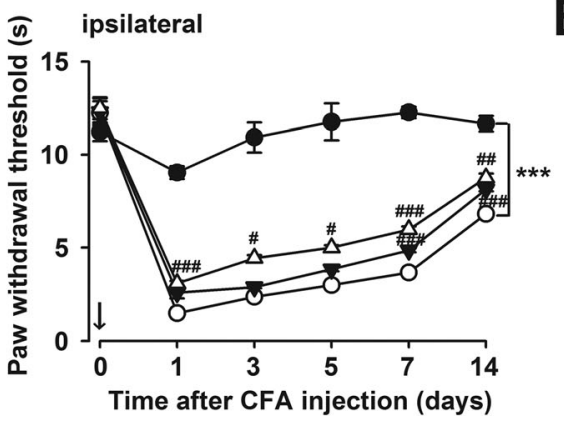

C

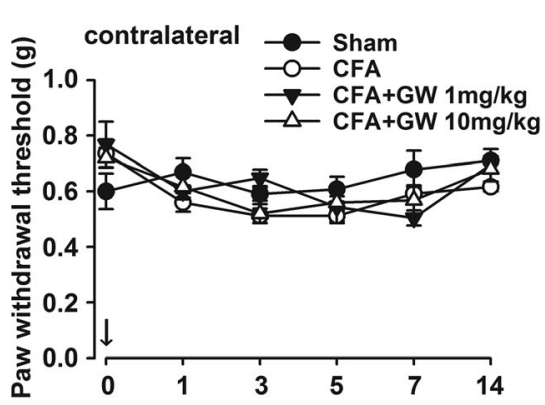

E

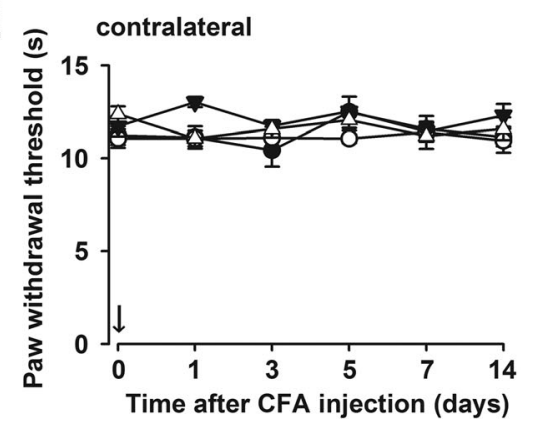

Fig. 2 LXRß activation by GW3965 reversed CFA-elicited persistent mechanical allodynia and thermal hyperalgesia. a Schematic illustration of the experiment procedure. b, c GW3965 (GW, $10 \mathrm{mg} / \mathrm{kg}$ ) provided relief of mechanical allodynia on the ipsilateral side and no effect on the contralateral side in CFA-treated mice. $\mathbf{d}$, e GW relieved thermal hyperalgesia on the ipsilateral side and had no effect on the contralateral side in CFA-treated mice. Error bars represent SEM. $n=5,{ }^{*} p<0.05,{ }^{* *} p<0.01,{ }^{* * *} p<0.001$ vs. Sham; $p<0.05,{ }^{\# \#} p<0.01,{ }^{\# \# \#} p<0.001$ vs. CFA-injected group

Isoform LXR $\beta$ mediated the analgesic effect of GW3965 Given the lack of selective agonists for LXR $\alpha$ and LXR $\beta$ isoforms, we applied specific shRNA-mediated knockdown of LXRs in ACC to test the roles of LXR $\alpha$ and LXR $\beta$ in the analgesic effects of GW (Fig. 3a). Knockdown of LXR $\beta$ expression by lentiviral microinjection into bilateral ACC completely eliminated GW-mediated analgesic effects $(p>0.05$, shLXR $\beta+$ CFA + GW vs. shNC + CFA group; Fig. 3d, h), whereas lentiviral shLXR $\alpha$ did not affect GWmediated analgesic effects in CIP mice $(p<0.05$, shLXR $\alpha+$ CFA + GW vs. shLXR $\alpha+$ CFA; Fig. 3b, f), suggesting that LXR $\beta$ isoform mediated the analgesic effect of GW. Consistent with preceding experiments, lentiviral $\operatorname{shLXR} \beta$ but not $\operatorname{shLXR} \alpha$ decreased withdrawal latency of thermal pain in the contralateral hindpaw of mice $(p<0.05$, shLXR $\beta$ vs. shNC; $p>0.05$, shLXR $\alpha$ vs. shNC; Fig. 3g, i). Moreover, lentiviral shLXR $\beta$ enhanced CFA-induced hyperalgesia $(p<0.05$,
shLXR $\beta+$ CFA vs. shNC + CFA; Fig. 3h), confirming $\mathrm{LXR} \beta$ isoform was involved in CIP development.

\section{Reduced nuclear factor- $\mathrm{KB}$ transcriptional activity in CFA- induced inflammatory chronic pain after GW3965 treatment}

Previous work reported that the anti-inflammatory effect of LXRs activation was mediated by NF- $\mathrm{B}$ inhibition [30-32]. Co-IP assay validated that LXR $\beta$ physically interacted with NF-kB p65 in the multiprotein complexes extracted from ACC (Fig. 4a, b). CFA injection induced an increase level of nuclear p65 and a decrease expression of cytoplasmic p65 correspondingly in ACC (Fig. 4d, e). GW treatment obviously reversed the enhanced nuclear translocation of p65 and p50 $(p<0.05$, CFA + GW vs. CFA; Fig. 4c, f-i), which compose the most common heterodimer of NF-kB. At the same time, GW administration corrected the elevated $\mathrm{p}-\mathrm{I} \kappa \mathrm{B} \alpha$ (phosphorylated NF-kB inhibitor alpha) $(p<0.001$, CFA + 


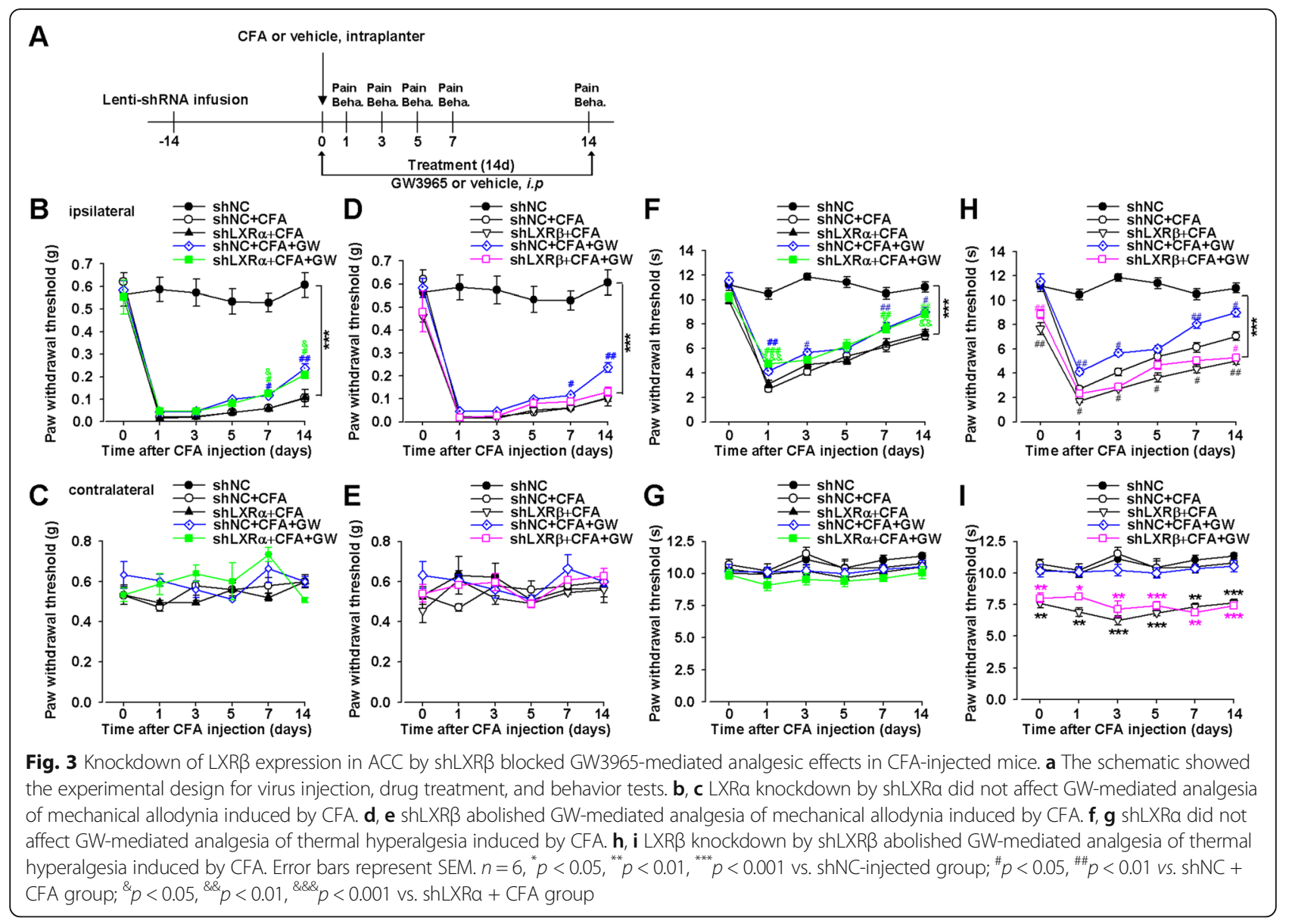

GW vs. CFA; Fig. 4j, k), which is a major indicator of NF- $\mathrm{KB}$ activity after CFA injection [33]. Collectively, GW administration inhibited the NF- $\mathrm{B}$ transcriptional activity and thus may suppress the inflammatory responses.

\section{GW3965 administration suppressed CFA-induced neuroinflammation}

Accumulating evidence indicates that the phosphorylated form of mitogen-activated protein kinase (MAPK) is involved in the induction and maintenance of both acute and inflammatory pain [34, 35]. CFA injection induced a higher amount of p-ERK and pJNK but not p-p38 expression in both shNC and shLXRs microinjection mice $(p<0.05$, shNC + CFA vs. shNC + Sham; shLXR $\alpha+$ CFA vs. shLXR $\alpha+$ Sham; $\operatorname{shLXR} \beta+$ CFA vs. $\operatorname{shLXR} \beta+$ Sham; Fig. 5). GW administration could inhibit the activated kinases $(p<0.01$, shNC + CFA + GW vs. shNC + CFA; Fig. $5 \mathrm{a}-\mathrm{d}, \mathrm{g}-\mathrm{j})$. Consistent with the behavior results, the downregulation of LXR $\beta$ by $\operatorname{shLXR} \beta$ partially abolished the effects of GW on MAPK phosphorylation, including $\mathrm{p}$-ERK and $\mathrm{p}$-JNK $(p>0.05$, shLXR $\beta$ + CFA + GW vs. shLXR $\beta$ + CFA; Fig. $5 g-j)$. However, the downregulation of LXR $\alpha$ by shLXR $\alpha$ did not affect GW-mediated inhibition of MAPK phosphorylation $(p<0.05$, shLXR $\alpha+$ CFA + GW vs. shLXR $\alpha+$ CFA; Fig. $5 \mathrm{a}-\mathrm{d})$. Thus, the reduction of activated MAPKs by GW via LXR $\beta$ activation alleviated pain behaviors in CFA-insulted mice.

Our previous study indicated that TNF- $\alpha$ in ACC was involved in CIP development [36]. As expected, GW treatment reversed the increase of TNF- $\alpha$ in ACC after CFA exposure $(p<0.05$, CFA + GW d1, d3 vs. CFA d1, $\mathrm{d} 3$ in serum; $p<0.05$, CFA + GW d1, d3, d5 vs. CFA d1, d3, d5 in ACC; Additional file 5: Figure S4a, b). The expression of ABCA1 and ApoE, which are LXR target genes, was determined to measure LXRs activation upon GW stimulation. ApoE expression was increased promptly from $\mathrm{d} 1$ to $\mathrm{d} 7$ both in serum and ACC after GW treatment $(p<0.05, \mathrm{CFA}+\mathrm{GW} \mathrm{d} 1,3,5,7$ vs. CFA $\mathrm{d} 1,3,5,7$ in serum; $p<0.05, \mathrm{CFA}+\mathrm{GW} \mathrm{d} 3, \mathrm{~d} 5$ vs. CFA $\mathrm{d} 3$, d5 in ACC; $p<0.01$, CFA + GW d1, d7 vs. CFA d1, d7; Additional file 5: Figure S4c, d); ABCA1 expression in ACC increased dramatically at $\mathrm{d} 1$ after GW administration, while the increase of ABCA1 in serum showed significant at $\mathrm{d} 5$ and $\mathrm{d} 7$ after GW administration $(p<$ $0.05, \mathrm{CFA}+\mathrm{GW}$ d7 vs. CFA d7 in serum, $p<0.01$, CFA 

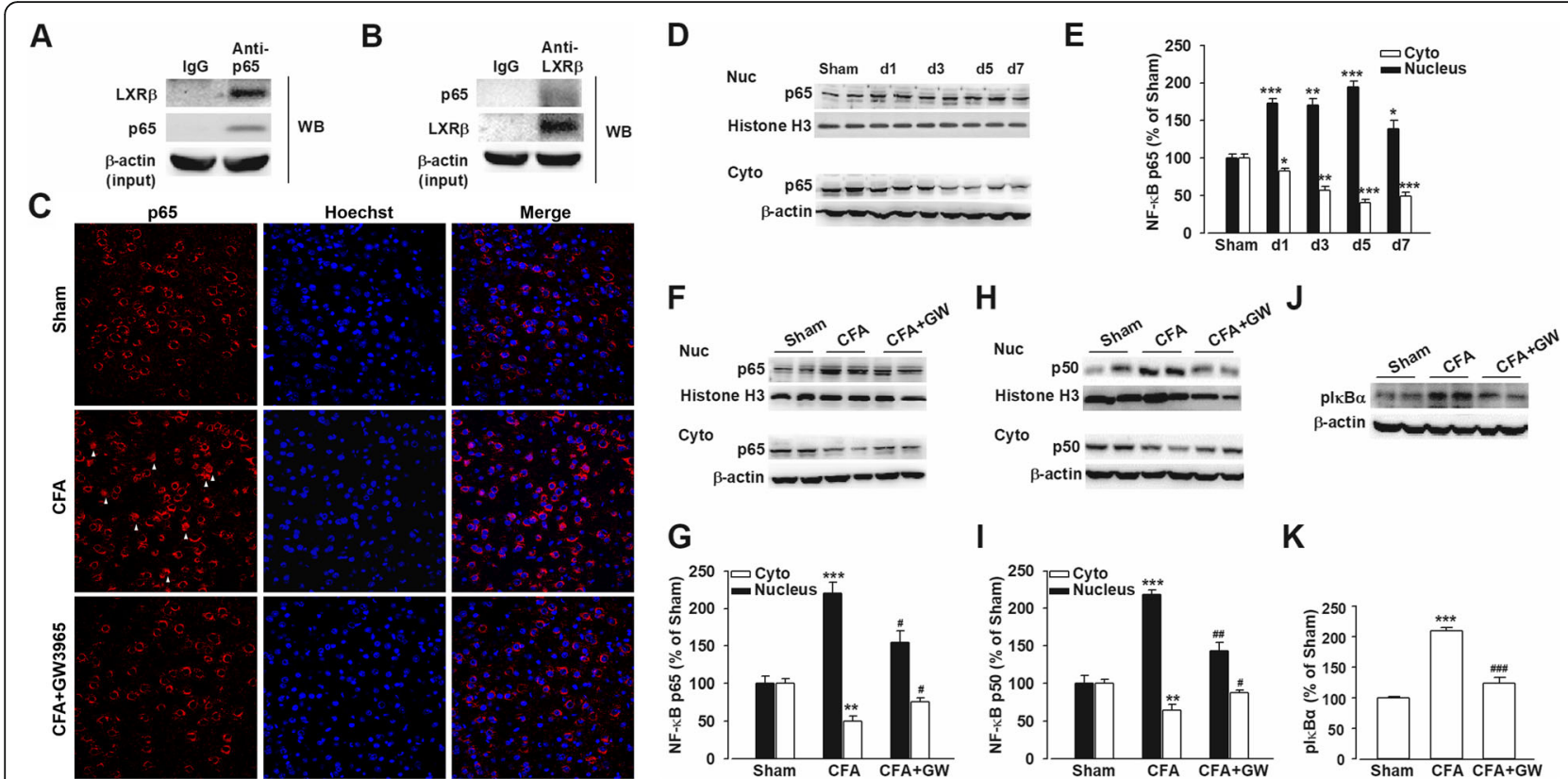

Fig. 4 GW3965 inhibited the increased nuclear translocation of NF-kB and MAPK phosphorylation in mice ACC after CFA injection. a, b Co-IP revealed the interaction of endogenous LXRß with NF-KB p65 in mouse ACC. c Representative images of nuclear translocation of NF-KB p65 in ACC from Sham, and mice after CFA injection with or without GW3965 administration (GW, 10 mg/kg) were stained for p65 (red) and Hoechst (blue). d, e The time course of p65 nuclear translocation in ACC after CFA insult. GW treatment (10 mg/kg) reversed the enhanced nuclear translocation of p65 (f, $\mathbf{g})$, p50 (h, i), and p-IKBa expression (j, k) after CFA injection. $n=5,{ }^{*} p<0.05,{ }^{* *} p<0.01,{ }^{* * *} p<0.001$ vs. Sham; ${ }^{\#} p<0.05,{ }^{\# \# \#} p<0.001$ vs. CFA-injected group

$+\mathrm{GW}$ d5 vs. CFA d5 in serum; $p<0.001, \mathrm{CFA}+\mathrm{GW}$ d1, d5, d7 vs. CFA d1, d5, d7 in ACC; Additional file 5: Figure S4e, f). Thereby, the data indicated that LXRs were activated in a ligand-dependent manner. Collectively, these data suggested that LXR activation suppressed CFA-induced inflammation.

\section{GW3965 administration suppressed the enhanced} synaptic transmission in the ACC from CFA-injected mice Previous studies evidenced that persistent inflammatory pain caused by CFA was due to an enhancement in excitatory synaptic transmission in ACC [17]. The expression pattern showed that LXR $\beta$ colocalized mainly in neuron ( $\beta$-tubulin III positive) and less in astrocyte (GFAP positive) and microglia (Iba-1 positive) in ACC (Additional file 6: Figure S5a-c). LXR $\beta$-positive neurons were mainly distributed in glutamatergic neurons (CAMK II $\alpha$ positive) and moderately in GABAergic neurons (GAD67 positive) as shown in Additional file 6: Figure $\mathrm{S} 5 \mathrm{~d}$, e. To demonstrate the possible mechanisms of LXR $\beta$ in CIP, excitatory postsynaptic currents (EPSCs) were recorded from layer II to III neurons of ACC. The slope of the input-output curve was significantly potentiated in slices from CFA-injected mice compared with Sham, which was obviously reduced by GW incubation $(p<0.01$, CFA vs. Sham; $p<0.05$, CFA + GW vs. CFA; Fig. $6 a, b)$, suggesting that LXRs activation reversed the increased synaptic efficacy in ACC neurons from CFA- injected mice. To further explore the role of GW in synaptic transmission after CFA injection, AMPA receptormediated mEPSCs, reflecting the release of single quanta of neurotransmitter, were measured. As expected, GW incubation could reverse the strengthened mEPSC frequency induced by CFA $(p<0.05, \mathrm{CFA}+\mathrm{GW}$ vs. CFA + Veh; Fig. $6 c-e)$. These findings provided evidence that GW inhibited the excitatory glutamatergic neurotransmission which was involved in pain development through LXRs activation. It is well evidenced that GluR1-containing AMPA receptors play crucial roles in pain and emotional disorders, especially the phosphorylation of GluR1 at Ser831/Ser845. We further found that GW administration reversed the hyperphosphorylation of GluR1 at Ser831 and Ser845 $(p<0.01$, CFA + GW vs. CFA; Fig. 6f-h) in mice ACC upon CFA injury.

\section{Reduction of LXR $\beta$ expression in CFA mice was associated} with enhanced activity of HDAC5

Evidence deciphered that epigenetic regulation plays a critical role in CIP development, and we revealed that the dysfunction of LXR $\beta$ induced by CFA insult led to mice analgesia. Thus, we further explored the epigenetic mechanisms on LXR $\beta$ regulation. Western blot analysis showed HDAC5 expression $(p<0.001$, CFA vs. Sham; Fig. 7a, b) but not HDAC2 expression elevated upon CFA injury ( $p>0.05$, CFA vs. Sham; Fig. 7a, b); HDAC5 expression was negatively correlated with that of LXR $\beta$ 


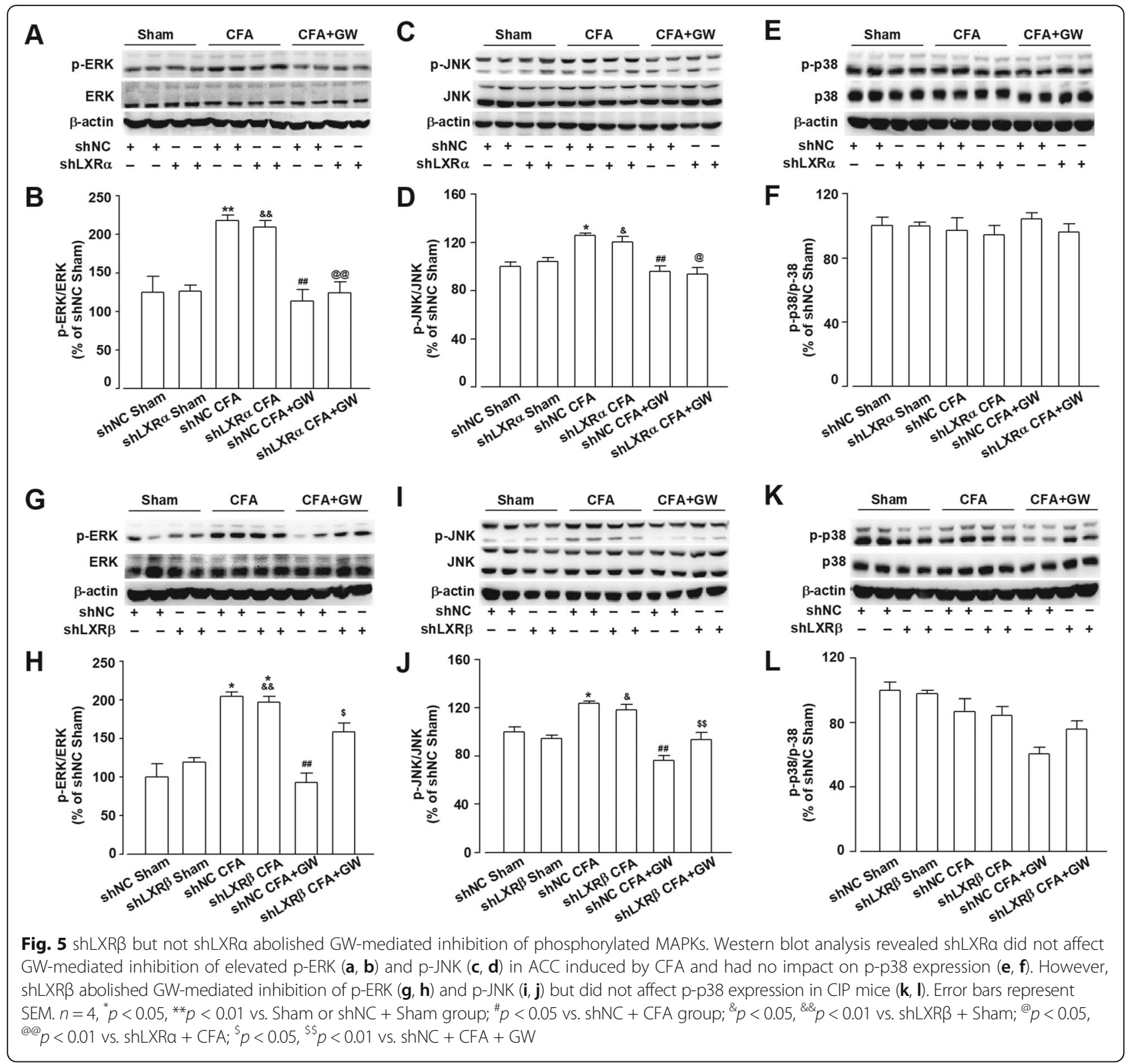

in ACC $(p<0.05$, CFA vs. Sham; Fig. 7a, b), suggesting that epigenetics might intervene in the expression of $L x r \beta$ gene, accompanied by pain sensation induced by CFA. To determine whether HDAC inhibited $L x r \beta$ expression, an in vitro culture system of neurons was applied. Incubation of cultured neurons with SAHA $(5 \mu \mathrm{M})$, a class I/IIb HDAC inhibitor, led to an induction of $\operatorname{Lxr} \beta$ mRNA expression ( $p<0.05$, SAHA vs. DMSO; Fig. $7 \mathrm{c}$ ), suggesting SAHA restored $L x r \beta$ gene expression by inhibiting HDAC activity. Meanwhile, SAHA induced global histone acetylation, including $\mathrm{AcH} 3$ and $\mathrm{AcH} 4$ levels in cultured neurons $(p<0.05$, SAHA vs. DMSO; Fig. $7 d, e)$, indicating that enhanced $\mathrm{AcH} 3$ and $\mathrm{AcH} 4$ were responsible for $\operatorname{Lxr} \beta$ induction. These data indicated that $L x r \beta$ expression was regulated by HDAC5.

Finally, to demonstrate the impacts of histone modifications on gene expression, a promoter analysis of $L x r \beta$ was performed to identify the potential regulatory regions where acetylated histones might bind. The total length of $2000 \mathrm{bp}$ upstream of the $\operatorname{Lxr} \beta$ transcription start site was analyzed, and four pairs of highly specific primers for $\operatorname{Lxr} \beta$ were designed. ChIP analysis was carried out to test the enrichment of acetylated histones at $L x r \beta$ promoter region in cortical neurons with or without SAHA treatment, validating by comparison to IgG control ChIP and promoter amplicon sequencing 

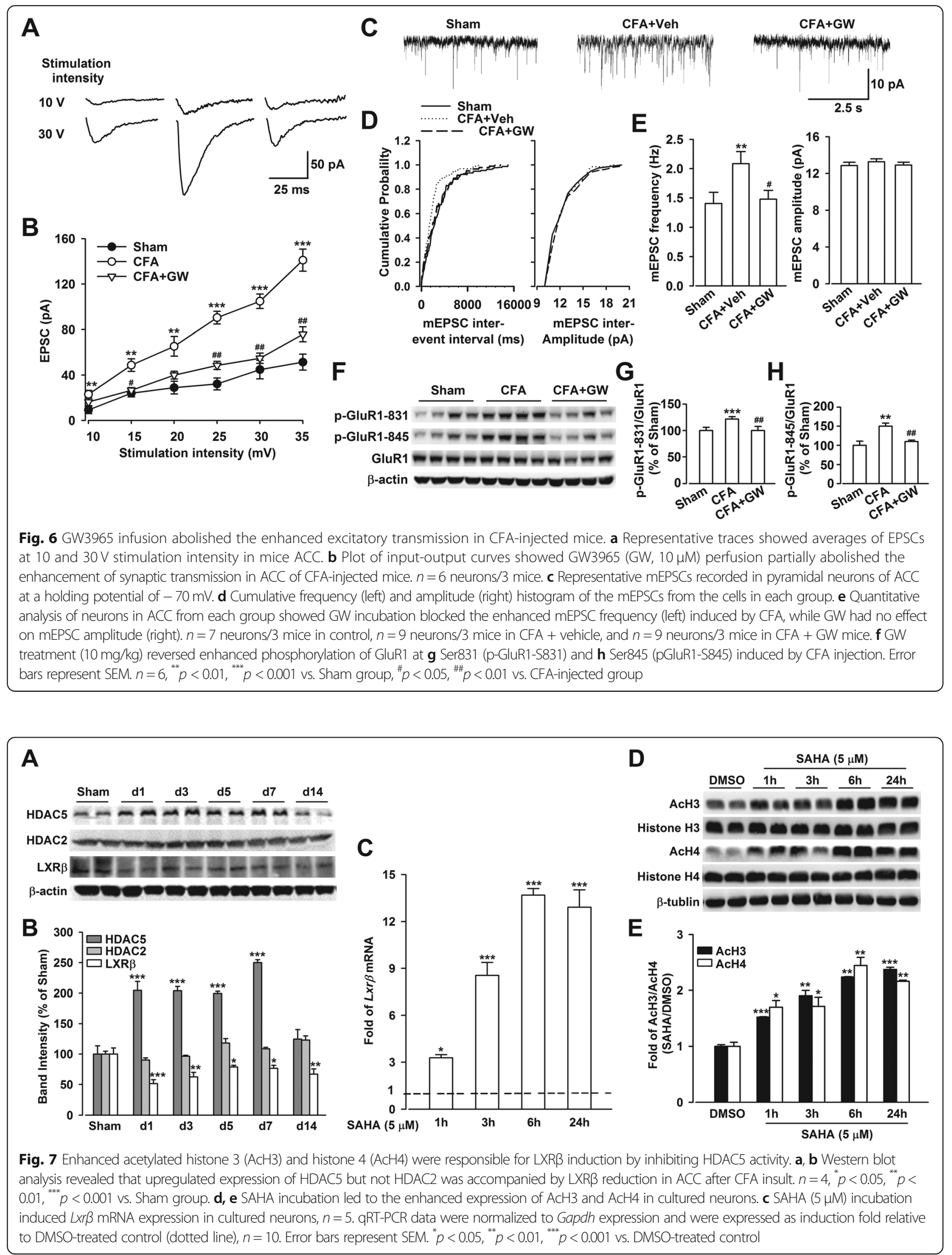


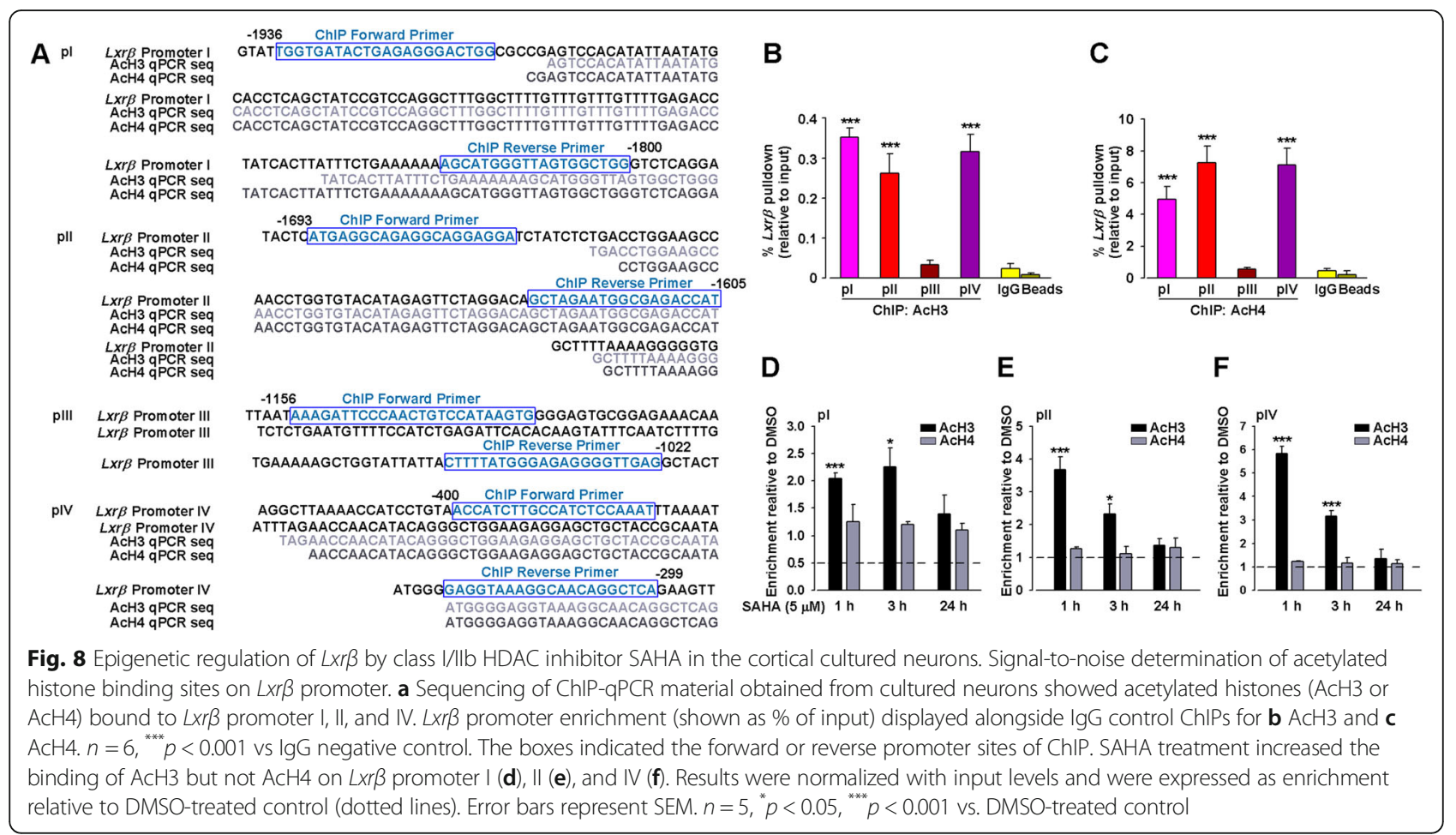

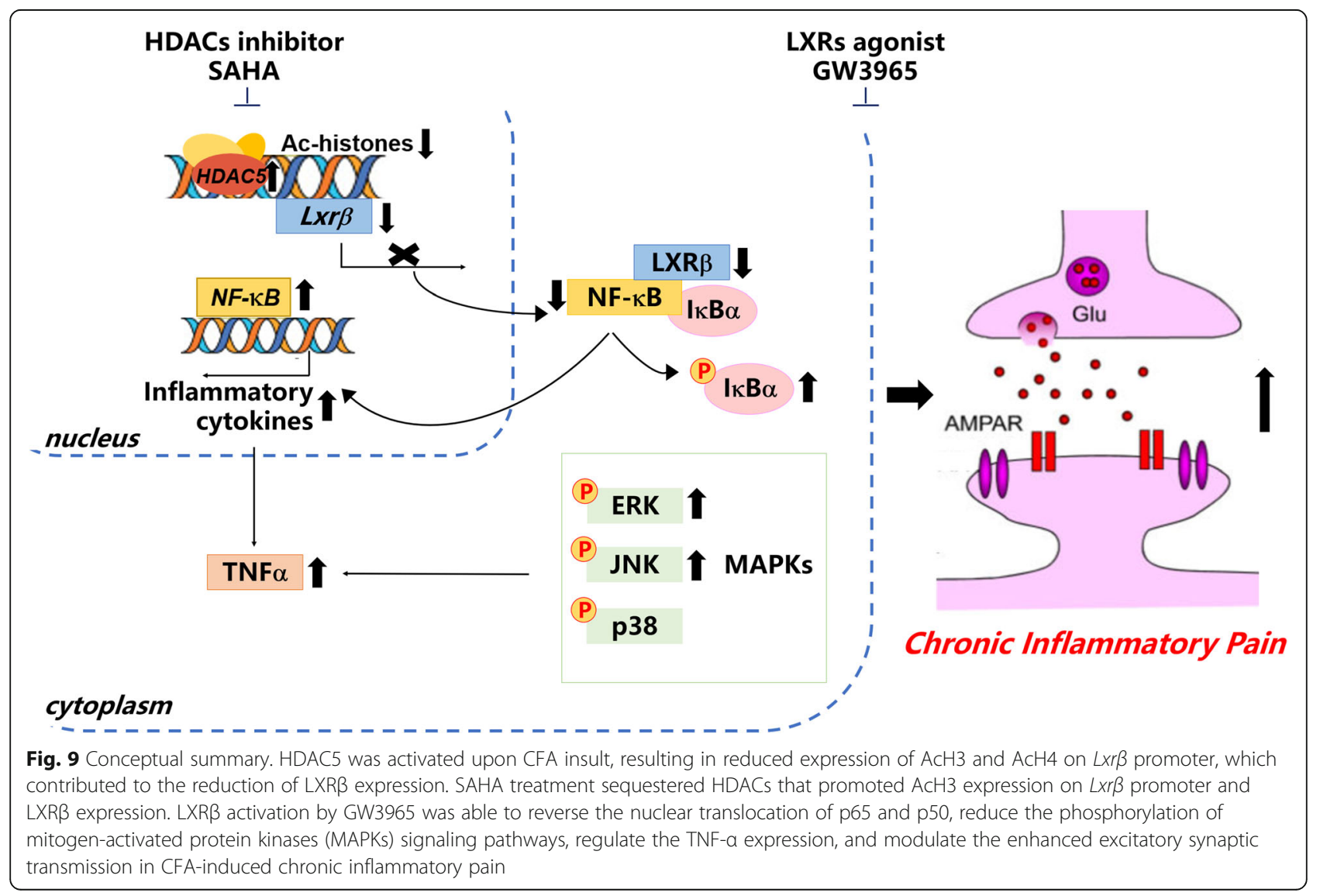


(Fig. 8a). Analysis revealed that $\mathrm{AcH} 3$ and $\mathrm{AcH} 4$ were bound to the regions of about $1900 \mathrm{bp}, 1600 \mathrm{bp}$, and 350 bp ( $p<0.001$, pI, II, IV vs. IgG; Fig. 8 b, c) but not 1100 bp ( $p>0.05$, pIII vs. IgG; Fig. 8 b, c) upstream of the transcription start site of $\operatorname{Lxr} \beta$ in cultured neurons.

Next, we asked if the dynamics of $\operatorname{Lxr} \beta$ mRNA induction by HDAC inhibition correlated with histone acetylation at respective promoters. We analyzed the expression levels of $\mathrm{AcH} 3$ and $\mathrm{AcH} 4$ at these promoters after SAHA treatment. Surprisingly, the levels of AcH3 but not AcH4 at $\operatorname{Lxr} \beta$ promoter I, II, and IV were robustly induced by SAHA treatment for $1 \mathrm{~h}$, followed by a gradual decrease in $24 \mathrm{~h}$ after SAHA treatment $(p<0.001$, SAHA $1 \mathrm{~h}, 3 \mathrm{~h}$ vs. DMSO; $p>0.05$, SAHA $24 \mathrm{~h}$ vs. DMSO for $\mathrm{AcH} 3 ; p>0.05$, SAHA vs. DMSO for AcH4; Fig. 8d-f). This was in sharp contrast with the relative induction of Lxr $\beta$ mRNA by SAHA treatment. Taken together, the epigenetic suppression of LXR $\beta$ in ACC by HDAC drove CFA-induced pain.

\section{Discussion}

In the current study, we have shown that LXR $\beta$ levels in ACC were reduced in mice with CFA-induced chronic pain and LXR $\beta$ knockdown in ACC led to pain sensation behaviors. LXR $\beta$ activation exerted analgesic effects through anti-inflammation and rebalancing the neurotransmission in CFA-induced pain model. ChIP analysis revealed that HDAC5 triggered histone deacetylation on the promoter region of $L x r \beta$, resulting in the downregulation of $L x r \beta$ transcription. Thus, our results suggest LXR $\beta$ activation may represent a potential novel target for the treatment of chronic pain and also provide a novel insight into the epigenetic mechanism underlying mechanisms of chronic pain (Fig. 9).

LXR $\beta$ mutation was involved in acute and inflammatory pain [37]. It has been demonstrated that activation of LXRs by GW, a synthetic full agonist for both LXR $\alpha$ and LXR $\beta$ isoforms, which can readily cross the blood-brain barrier to exert its specific actions in brain, exerted an antinociceptive effect in rat joint pain and diabetes-caused thermal hyperalgesia [38, 39], suggesting that the dysfunction of LXRs contributes to pain pathogenesis. We also found that CFA induced the reduction of LXR $\beta$ levels in mice ACC along with hyperalgesia (Fig. 1). And LXR agonist, GW administration did not change the expression of LXRs, indicating that the GW-mediated inhibition of mechanical allodynia and thermal hyperalgesia was through activating LXR $\beta$ but not the expression of LXR $\beta$. Moreover, the knockdown of LXR $\beta$ levels in ACC by shRNA led to thermal hyperalgesia, which manifested as shorter latencies in a plantar analgesia device, further implying that the downregulation of LXR $\beta$ in ACC contributed to the etiology of chronic pain. Moreover, we first demonstrated GW administration reversed CFA-induced pain behaviors (Fig. 2), confirming the analgesic effects of GW. Given the lack of LXR $\beta$ isoform-specific agonist and antagonist, we used shRNA-mediated knockdown of LXR $\beta$ isoform to further validate the roles of LXR $\beta$ in the analgesic effects of GW. Microinjections of the shLXR $\beta$ into ACC bilaterally before GW treatment completely abrogated the analgesic effects of GW (Fig. 3), thereby indicating that LXR $\beta$ isoform mediated the analgesic effects of GW. Furthermore, LXR $\beta$ was also expressed in the spinal cord, and male LXR $\beta^{-/-}$mice suffered from adult-onset motor neuron degeneration, whereas LXR $\beta$ activation by T0901317 and GW protected the spinal cord from injury. Our results showed downregulated LXR $\beta$ in bilateral ACC, and GW-mediated analgesic effect was almost blocked, indicating the important role of LXR $\beta$ of ACC in pain modulation. We cannot exclude the effects of GW mediated by activating endogenous LXRs in the spinal cord by i.p administration. Therefore, the different routes of GW administration, such as intrathecal or intraventricular injection, could be further conducted and explored to confirm the activated effects of GW on ACC LXR $\beta$ in pain regulation.

Evidence indicated the epigenetic mechanisms controlling central sensitization for persistent pain, especially histone acetylation/deacetylation. Histone acetylation is often associated with many transcription factors, archiving a given pattern of gene expression, whereas deacetylation is thought to suppress gene expression. HDAC inhibitors (HDACi) or increase of histone acetylation is able to attenuate persistent pain-associated inflammation $[18,40]$, supporting the analgesic effect of histone acetylation which was involved in the development of chronic pain. HDAC5 is a crucial member of class I HDACs and a promising candidate in pain modulation, and we observed the downregulation of LXR $\beta$ was associated with HDAC5 induction in ACC from CFA-insulted mice (Fig. 7a, b). Inhibition of HDAC5 by SAHA in cultured neurons led to the induction of AcH3 and $\operatorname{Lxr} \beta$ (Fig. 7ce), and ChIP data showed a significant binding of histone acetylation to the promoters of $\operatorname{Lxr} \beta$ (Fig. 8), indicating that LXR $\beta$ was a downstream target of HDAC5 in ACC of CIP mice. This data suggested that HDAC5 induced the deacetylation of $\operatorname{Lxr} \beta$ gene with high selectivity, providing direct evidence that suppression of LXR $\beta$ in CIP was potentially regulated by histone acetylation/ deacetylation. In this study, the HDAC5 participation in the suppression of LXR $\beta$ in CIP was specifically confirmed for the first time.

Central sensitization is triggered by NF- $\mathrm{kB}$-related proinflammatory mediators, including the cytokines TNF- $\alpha$ and IL- $1 \beta$, which can act directly on their receptors or targets to reduce pain thresholds, leading to inflammatory pain and hyperalgesia [36, 41]. We found that activation of LXR $\beta$ by GW decreased the CFA- 
induced production of cytokines such as TNF- $\alpha$ (Additional file 5: Figure S4) and NF-kB (Fig. 4) in ACC. Thus, we infer that an LXR $\beta$-dependent mechanism regulating the synthesis or release of pro-inflammatory chemokines such as TNF- $\alpha$ through NF- $\kappa B$ pathway may mediate the inflammatory response to CFA. This might explain reduced pain response by $\mathrm{GW}$ treatment in CFA test.

MAPK family is phosphorylated upon various types of noxious stimuli $[35,42]$. Accumulating evidence indicates that exaggerated inflammatory nociception has been associated with ERK and JNK activation in different pain-relevant tissues during acute and chronic experimental pain [43]. In the current study, we demonstrated that GW treatment completely abolished the induction of p-ERK and p-JNK upon CFA injury (Fig. 5), thereby implying that inhibition of inflammation may also be involved in the analgesic effects mediated by LXR $\beta$ activation.

Recent studies from animals and humans demonstrate the critical importance of ACC neurons in behavioral nociceptive responses to injury, whereas it governs or integrates pain perception or unpleasant moods in humans $[44,45]$. Indeed, ACC is one of the key nodes in a complex network of cortical and subcortical structures that process and regulate pain behavior and aversion. Chronic pain increases the basal and noxious stimulusinduced firing rates in ACC; thus, an enhancement of neuron activities in ACC may play complementary roles in the chronic pain state [46, 47]. Inflammatory stimuli lead to the consequent modulation of synaptic transmission and neuronal excitability, which are involved in pain facilitation [48]. Our study is the first time to examine whether LXR activation reversed altered synaptic transmission in ACC of mice with CIP. Our previous study demonstrated an enhancement of synaptic transmission in ACC of animals suffering from CIP [17]. Our results demonstrated that GW abolished the increased excitatory neurotransmission in ACC induced by CFA (Fig. 6). Collectively, we provide evidence for the roles of LXRmediated analgesic effects, which were likely to be achieved through both anti-inflammation and neurotransmitter rebalance.

Moreover, evidence links endoplasmic reticulum stress (ERS) to chronic pain [49-51], especially obesity-induced allodynia in mice, while the activation of LXRs alleviates the allodynia through delaying ERS [52]. We also found that GW administration reversed the activated ERS in CIP mice, measured by the enhanced expression of ERS markers, C/EBP homologous protein $(\mathrm{CHOP})$, and activating transcription factor 4 (ATF4) in ACC (Additional file 7: Figure S6) by $\mathrm{qPCR}$, indicating that LXR activation attenuated ERS in CIP.
Despite the potential analgesic effects, unfortunately, $\mathrm{LXR} \alpha / \beta$ dual agonists, including GW, may elevate hepatic and serum triglyceride levels. Elevated plasma or hepatic triglyceride levels are unacceptable side effects for $L X R \alpha / \beta$ dual agonists due to the risks of cardiovascular diseases and hepatotoxicity. LXR $\alpha$ is the main isoform responsible for the deleterious triglyceride-raising effects of full LXR agonists. Therefore, developing selective agonists for LXR $\beta$ isoform to eliminate the adverse effect of increased triglyceride is still needed. Our findings support that LXR $\beta$ levels in ACC were negatively correlated with pain behaviors. The analgesic effects mediated by LXR $\beta$ activation were likely through anti-inflammation pathways. Thus, the reduced LXR $\beta$ level by epigenetic regulation may be implicated in the etiology of chronic pain, and LXR $\beta$ activation may represent a potential novel target for the treatment of chronic pain.

\section{Conclusion}

In conclusion, our study reveals the analgesic effects of LXR $\beta$ activation are associated with the regulation of neuroinflammation and central sensitization in CFA-induced inflammatory pain. Our research provides, for the first time, a novel epigenetic mechanism that the reduced LXR $\beta$ level by histone modification accounts for the etiology of chronic pain. In brief, (1) LXR $\beta$ deficits in ACC were involved in chronic inflammatory pain. (2) LXR $\beta$ knockdown by lentiviral shRNA in ACC led to hyperalgesia. (3) LXR $\beta$ activation by agonist GW exerted analgesic effect by inhibiting inflammation responses and enhanced excitatory neurotransmission in ACC. (4) Elevated HDAC5 expression was negatively correlated with that of LXR $\beta$ in ACC in chronic inflammatory pain. HDAC5 triggered histone deacetylation on the promoter region of $L x r \beta$, resulting in the downregulation of $L x r \beta$ transcription. Therefore, our results might provide not only a better understanding of the role and regulatory mechanism of LXR $\beta$ in CIP but also a novel therapeutic target for chronic pain.

\section{Additional files}

Additional file 1: Table S1. PCR primers and data analysis used in this study. (DOCX $50 \mathrm{~kb}$ )

Additional file 2: Figure S1. The expression of $L X R a$ and $L X R \beta$ in mice ACC. The brain slices containing ACC were collected and applied to immunofluorescent staining. a Representative immunofluorescent images of ACC labeled with LXRa (green), LXRß (red), and Hoechst 33258 (blue) in mice. LXR $\beta$ was widely expressed in ACC, while LXRa was scarely expressed. Scale bars $=100 \mu \mathrm{m}$. (TIF $1038 \mathrm{~kb}$ )

Additional file 3: Figure S2. The expression of $L X R \beta$ but not $L X R a$ decreased in ACC after CFA paw injection. a Representative Western blot of LXRa levels in ACC on day 1, 3, 5, 7, and 14 after CFA injection. b The histogram showed summarized data of a normalized to an internal control and expressed as a relative value. c Representative Western blot of downregulated LXR $\beta$ levels in ACC on day 1, 3, 5, 7, and 14 after CFA 
injection. $d$ The histogram showed summarized data of c normalized to an internal control and expressed as a relative value. Error bars represent SEM. $n=5,{ }^{* * *} p<0.01,{ }^{* * * *} p<0.001$ vs. Sham group. (TIF $483 \mathrm{~kb}$ )

Additional file 4: Figure S3. Microinjection of lentiviral shRNAs into ACC did not alter mice locomotor activities. a Representative traveling tracks in OFT showed no difference in the total distance in each group b, and the time spent in the center arena $\mathrm{c}$ in shNC-, shLXRa-, and shLXRßinfected group. $d$ shNC, shLXRa, and shLXRß infection had no effect on retention time of mice on rotarod. Error bars represent SEM. $n=5$ for each group. (TIF $611 \mathrm{~kb}$ )

Additional file 5: Figure S4. GW3965 reversed CFA-mediated TNF-a induction by LXR activation. ELISA analysis revealed GW $(10 \mathrm{mg} / \mathrm{kg})$ treatment inhibited TNF-a induction in a serum and b ACC after CFA injection. GW treatment increased the levels of $c, d A p o E$ and e, $A B C A 1$ in serum and ACC. Error bars represent SEM. $n=5,{ }^{*} p<0.05,{ }^{* *} p<0.01$ vs. Sham group; ${ }^{\#} p<0.05, \# p<0.01, \# \#<0.001$ vs. CFA-injected group. (TIF $101 \mathrm{~kb}$ )

Additional file 6: Figure S5. The cellular pattern of LXRß colocalization in mice ACC. The brain slices containing ACC were stained for a1-a4 $\beta$ tubulin III+LXRß, b1-b4 GFAP+LXRß, c1-c4 Iba-1+LXRß, d1-d4 CAMK $\| a+L X R \beta$, and e1-e4 GAD67+LXRß. LXR $\beta$ colocalized mainly with glutamatergic neurons (CAMK Ila positive), moderately with GABAergic neurons (GAD67 positive), a small part in microglia (lba-1 positive) and in astrocyte (GFAP positive) in ACC. $\beta$-tubulin III, GFAP, Iba-1, CAMK Ila, and GAD67 showed in green, LXRß showed in red, and Hoechst in blue. Scale bars $=100 \mu \mathrm{m}$. (TIF $2467 \mathrm{~kb})$

Additional file 7: Figure S6. GW3965 protected ER stress in ACC of CIP mice. a GW reversed mRNA levels of ER stress markers, CHOP and ATP4, in ACC of CIP mice. Error bars represent SEM. $n=4,{ }^{*} p<0.05,{ }^{* *} p<0.01$ vs. Sham group; $" p<0.05$ vs. CFA-injected group. (TIF $62 \mathrm{~kb}$ )

\section{Abbreviations}

ABCA1: ATP-binding cassette transporter; ACC: Anterior cingulate cortex; AMPA: a-Amino-3-hydroxy-5-methyl-4-isoxazolepropionic acid; CFA: Complete Freund's adjuvant; ChIP: Chromatin immunoprecipitation; CIP: Chronic inflammatory pain; CNS: Central nervous system; Co-IP: Coimmunoprecipitation; ELISA: Enzyme-linked immunosorbent assay; EPSCs: Excitatory postsynaptic currents; ERK: Extracellular regulated protein kinases; HDAC5: Histone deacetylase 5; HDACi: HDAC inhibitor; IkBa: NFkappa-B inhibitor alpha; JNK: c-Jun N-terminal kinase; LXRs: Liver X receptors; MAPKs: Mitogen-activated protein kinases; mEPSC: Miniature EPSC; NFKB: Nuclear factor-KB; shNC: Negative shRNA for LXRs; shRNA: Short hairpin RNA; TNF-a: Tumor necrosis factor-a

\section{Acknowledgements}

Not applicable.

\section{Authors' contributions}

YJL, YMW, and MGZ participated in the research design. YJL, KZ, TS, YYG, and LY conducted the experiments. JW, YJL, QY, and SBL contributed the reagents or analytical tools. YJL performed the data analysis. YJL, YMW, and MGZ wrote or contributed to the writing of the manuscript. All authors read and approved the final manuscript.

\section{Funding}

This work was supported by the National Natural Science Foundation of China (No.81571328 and No.81771469) and Major International Cooperation in Shaanxi (2017KW-ZD-01 for Prof. Liu).

\section{Availability of data and materials}

The datasets supporting the conclusions of this article are included within the article and its additional files. All material used in this manuscript will be made available to researchers subject to confidentiality.

\section{Ethics approval and consent to participate}

All experimental protocols and procedures were approved by the Fourth Military Medical University Animal Care and Use Committee (TDLL2018-03164) and carried out in accordance with the Guide for the Care and Use of Laboratory Animals of the National Institutes of Health.

\section{Consent for publication}

Not applicable.

\section{Competing interests}

The authors declare that they have no competing interests.

\section{Author details}

'Department of Pharmacy, Precision Pharmacy \& Drug Development Center, The Second Affiliated Hospital, Fourth Military Medical University, Xi'an 710038, Shaanxi Province, People's Republic of China. ${ }^{2}$ Department of Pharmacology, School of Pharmacy, Fourth Military Medical University, Xi'an 710032, Shaanxi Province, People's Republic of China. ${ }^{3}$ Department of Ambulatorium, 94750 Army Hospital, Liancheng 366200, FuJian Province, People's Republic of China. ${ }^{4}$ Department of Acupuncture and Moxibustion, Xi'an Hospital of Traditional Chinese Medicine, Xi'an 710021, Shaanxi Province, People's Republic of China.

Received: 7 January 2019 Accepted: 21 May 2019 Published online: 29 June 2019

\section{References}

1. Campbell JN, Meyer RA. Mechanisms of neuropathic pain. Neuron. 2006;52: 77-92.

2. Barthas F, Sellmeijer J, Hugel S, Waltisperger E, Barrot M, Yalcin I. The anterior cingulate cortex is a critical hub for pain-induced depression. Biol Psychiatry. 2015;77:236-45

3. Niederberger E, Resch E, Parnham MJ, Geisslinger G. Drugging the pain epigenome. Nat Rev Neurol. 2017;13:434-47.

4. Theofilopoulos S, Wang Y, Kitambi SS, Sacchetti P, Sousa KM, Bodin K, Kirk J, Salto C, Gustafsson M, Toledo EM, et al. Brain endogenous liver X receptor ligands selectively promote midbrain neurogenesis. Nat Chem Biol. 2013;9: 126-33.

5. Peet DJ, Turley SD, Ma W, Janowski BA, Lobaccaro JM, Hammer RE, Mangelsdorf DJ. Cholesterol and bile acid metabolism are impaired in mice lacking the nuclear oxysterol receptor LXR alpha. Cell. 1998;93:693-704.

6. Fan X, Kim HJ, Bouton D, Warner M, Gustafsson JA. Expression of liver $X$ receptor beta is essential for formation of superficial cortical layers and migration of later-born neurons. Proc Natl Acad Sci U S A. 2008; 105:13445-50

7. Wang L, Schuster GU, Hultenby K, Zhang Q, Andersson S, Gustafsson JA. Liver $X$ receptors in the central nervous system: from lipid homeostasis to neuronal degeneration. Proc Natl Acad Sci U S A. 2002;99:13878-83.

8. Xu P, Xu H, Tang $X, X u L$, Wang $Y$, Guo L, Yang Z, Xing Y, Wu Y, Warner $M$, et al. Liver $X$ receptor beta is essential for the differentiation of radial glial cells to oligodendrocytes in the dorsal cortex. Mo Psychiatry. 2014;19:947-57.

9. Andersson S, Gustafsson N, Warner M, Gustafsson JA. Inactivation of liver X receptor beta leads to adult-onset motor neuron degeneration in male mice. Proc Natl Acad Sci U S A. 2005:102:3857-62.

10. Paterniti I, Genovese T, Mazzon E, Crisafulli C, Di Paola R, Galuppo M, Bramanti $P$, Cuzzocrea $S$. Liver $X$ receptor agonist treatment regulates inflammatory response after spinal cord trauma. J Neurochem. 2010;112: 611-24.

11. Nicholson A, Kuper $H$, Hemingway $H$. Depression as an aetiologic and prognostic factor in coronary heart disease: a meta-analysis of 6362 events among 146538 participants in 54 observational studies. Eur Heart J. 2006; 27:2763-74

12. Cui X, Chopp M, Zhang Z, Li R, Zacharek A, Landschoot-Ward J, Venkat $P$, Chen J. ABCA1/ApoE/HDL pathway mediates GW3965-induced neurorestoration after stroke. Stroke. 2017:48:459-67.

13. Denk F, McMahon SB. Chronic pain: emerging evidence for the involvement of epigenetics. Neuron. 2012;73:435-44.

14. Fuchs PN, Peng YB, Boyette-Davis JA, Uhelski ML. The anterior cingulate cortex and pain processing. Front Integr Neurosci. 2014;8:35.

15. Bushnell MC, Ceko M, Low LA. Cognitive and emotional control of pain and its disruption in chronic pain. Nat Rev Neurosci. 2013;14:502-11.

16. Buffington AL, Hanlon CA, McKeown MJ. Acute and persistent pain modulation of attention-related anterior cingulate $\mathrm{fMRI}$ activations. Pain 2005;113:172-84. 
17. Zhao MG, Ko SW, Wu LJ, Toyoda H, Xu H, Quan J, Li J, Jia Y, Ren M, Xu ZC, et al. Enhanced presynaptic neurotransmitter release in the anterior cingulate cortex of mice with chronic pain. J Neurosci. 2006;26:8923-30.

18. Bai G, Ren K, Dubner R. Epigenetic regulation of persistent pain. Transl Res, 2015;165:177-99

19. Wang DS, Tian Z, Guo YY, Guo HL, Kang WB, Li S, Den YT, Li XB, Feng B, Feng $D$, et al. Anxiolytic-like effects of translocator protein (TSPO) ligand ZBD-2 in an animal model of chronic pain. Mol Pain. 2015;11:16.

20. Wang GQ, Cen C, Li C, Cao S, Wang N, Zhou Z, Liu XM, Xu Y, Tian NX, Zhang $Y$, et al. Deactivation of excitatory neurons in the prelimbic cortex via Cdk5 promotes pain sensation and anxiety. Nat Commun. 2015;6:7660.

21. Narita M, Kaneko C, Miyoshi K, Nagumo Y, Kuzumaki N, Nakajima M, Nanjo K, Matsuzawa K, Yamazaki M, Suzuki T. Chronic pain induces anxiety with concomitant changes in opioidergic function in the amygdala. Neuropsychopharmacology. 2006;31:739-50

22. Yalcin I, Bohren Y, Waltisperger E, Sage-Ciocca D, Yin JC, Freund-Mercier MJ, Barrot M. A time-dependent history of mood disorders in a murine model of neuropathic pain. Biol Psychiatry. 2011;70:946-53.

23. Hargreaves K, Dubner R, Brown F, Flores C, Joris J. A new and sensitive method for measuring thermal nociception in cutaneous hyperalgesia. Pain. 1988;32:77-88

24. Chen Y, Duan Y, Kang Y, Yang X, Jiang M, Zhang L, Li G, Yin Z, Hu W, Dong $P$, et al. Activation of liver $X$ receptor induces macrophage interleukin-5 expression. J Biol Chem. 2012;287:43340-50.

25. Yang L, Wang M, Guo YY, Sun T, Li YJ, Yang Q, Zhang K, Liu SB, Zhao MG, Wu YM. Systemic inflammation induces anxiety disorder through CXCL12/ CXCR4 pathway. Brain Behav Immun. 2016.

26. Gu B, Nakamichi N, Zhang WS, Nakamura Y, Kambe Y, Fukumori R, Takuma K, Yamada K, Takarada T, Taniura H, et al. Possible protection by notoginsenoside R1 against glutamate neurotoxicity mediated by $\mathrm{N}$-methylD-aspartate receptors composed of an NR1/NR2B subunit assembly. J Neurosci Res. 2009;87:2145-56.

27. Robison AJ, Vialou V, Sun HS, Labonte B, Golden SA, Dias C, Turecki G, Tamminga C, Russo S, Mazei-Robison M, et al. Fluoxetine epigenetically alters the CaMKllalpha promoter in nucleus accumbens to regulate DeltaFosB binding and antidepressant effects. Neuropsychopharmacology. 2014;39:1178-86

28. Koppel I, Timmusk T. Differential regulation of Bdnf expression in cortical neurons by class-selective histone deacetylase inhibitors. Neuropharmacology. 2013;75:106-15.

29. Li Q, Huang XJ, He W, Ding J, Jia JT, Fu G, Wang HX, Guo LJ. Neuroprotective potential of fasudil mesylate in brain ischemia-reperfusion injury of rats. Cell Mol Neurobiol. 2009;29:169-80.

30. Zelcer $\mathrm{N}$, Tontonoz P. Liver $\mathrm{X}$ receptors as integrators of metabolic and inflammatory signaling. J Clin Invest. 2006;116:607-14.

31. Zelcer N, Khanlou N, Clare R, Jiang Q, Reed-Geaghan EG, Landreth GE, Vinters HV, Tontonoz P. Attenuation of neuroinflammation and Alzheimer's disease pathology by liver x receptors. Proc Natl Acad Sci U S A. 2007;104:10601-6.

32. Cheng O, Ostrowski RP, Liu W, Zhang JH. Activation of liver $X$ receptor reduces global ischemic brain injury by reduction of nuclear factor-kappaB. Neuroscience. 2010;166:1101-9.

33. Morales JR, Ballesteros I, Deniz JM, Hurtado O, Vivancos J, Nombela F, Lizasoain I, Castrillo A, Moro MA. Activation of liver $X$ receptors promotes neuroprotection and reduces brain inflammation in experimental stroke. Circulation. 2008;118:1450-9.

34. Cao J, Wang JS, Ren XH, Zang WD. Spinal sample showing p-JNK and P38 associated with the pain signaling transduction of glial cell in neuropathic pain. Spinal Cord. 2015;53:92-7

35. Dai ZK, Lin TC, Liou JC, Cheng KI, Chen JY, Chu LW, Chen IJ, Wu BN. Xanthine derivative KMUP-1 reduces inflammation and hyperalgesia in a bilateral chronic constriction injury model by suppressing MAPK and NFkappaB activation. Mol Pharm. 2014;11:1621-31.

36. Jia D, Gao GD, Liu Y, He SM, Zhang XN, Zhang YF, Zhao MG. TNF-alpha involves in altered prefrontal synaptic transmission in mice with persistent inflammatory pain. Neurosci Lett. 2007;415:1-5.

37. Bao X, Cai Y, Wang Y, Zhao J, He X, Yu D, Huang J, Jing S, Du Z, Yang T, et al. Liver $X$ receptor beta is involved in formalin-induced spontaneous pain. Mol Neurobiol. 2017;54:1467-81.

38. Li N, Rivera-Bermudez MA, Zhang M, Tejada J, Glasson SS, Collins-Racie LA, Lavallie ER, Wang Y, Chang KC, Nagpal S, et al. LXR modulation blocks prostaglandin E2 production and matrix degradation in cartilage and alleviates pain in a rat osteoarthritis model. Proc Natl Acad Sci U S A. 2010; 107:3734-9.

39. Cermenati G, Abbiati F, Cermenati S, Brioschi E, Volonterio A, Cavaletti G, Saez E, De Fabiani E, Crestani M, Garcia-Segura LM, et al. Diabetes-induced myelin abnormalities are associated with an altered lipid pattern: protective effects of LXR activation. J Lipid Res. 2012;53:300-10.

40. Matsushita Y, Araki K, Omotuyi O, Mukae T, Ueda H. HDAC inhibitors restore C-fibre sensitivity in experimental neuropathic pain model. Br J Pharmacol. 2013;170:991-8.

41. Verri WA Jr, Cunha TM, Parada CA, Poole S, Cunha FQ, Ferreira SH. Hypernociceptive role of cytokines and chemokines: targets for analgesic drug development? Pharmacol Ther. 2006;112:116-38.

42. Obata K, Noguchi K. MAPK activation in nociceptive neurons and pain hypersensitivity. Life Sci. 2004;74:2643-53.

43. Ji RR, RWt G, Malcangio M, Strichartz GR. MAP kinase and pain. Brain Res Rev. 2009;60:135-48.

44. Wei F, Wang GD, Kerchner GA, Kim SJ, Xu HM, Chen ZF, Zhuo M. Genetic enhancement of inflammatory pain by forebrain NR2B overexpression. Nat Neurosci. 2001:4:164-9.

45. Wu LJ, Toyoda H, Zhao MG, Lee YS, Tang J, Ko SW, Jia YH, Shum FW, Zerbinatti $\mathrm{CV}, \mathrm{Bu} \mathrm{G}$, et al. Upregulation of forebrain NMDA NR2B receptors contributes to behavioral sensitization after inflammation. J Neurosci. 2005; 25:11107-16.

46. Zhang Y, Wang N, Wang JY, Chang JY, Woodward DJ, Luo F. Ensemble encoding of nociceptive stimulus intensity in the rat medial and lateral pain systems. Mol Pain. 2011;7:64.

47. Kung JC, Su NM, Fan RJ, Chai SC, Shyu BC. Contribution of the anterior cingulate cortex to laser-pain conditioning in rats. Brain Res. 2003;970:58-72.

48. Zhuo M. Cortical excitation and chronic pain. Trends Neurosci. 2008;31:199-207.

49. Ge Y, Jiao Y, Li P, Xiang Z, Li Z, Wang L, Li W, Gao H, Shao J, Wen D, et al. Coregulation of endoplasmic reticulum stress and oxidative stress in neuropathic pain and disinhibition of the spinal nociceptive circuitry. Pain. 2018:159:894-906.

50. Gui Y, Li A, Zhang J, Li G, Ruan X, Guo Q, Zou W. Alpha-asarone alleviated chronic constriction injury-induced neuropathic pain through inhibition of spinal endoplasmic reticulum stress in an liver $\mathrm{X}$ receptor-dependent manner. Anesth Analg. 2018;127:775-83.

51. Inceoglu B, Bettaieb A, Trindade da Silva CA, Lee KS, Haj FG, Hammock BD. Endoplasmic reticulum stress in the peripheral nervous system is a significant driver of neuropathic pain. Proc Natl Acad Sci U S A. 2015;112: 9082-7.

52. Gavini CK, Bookout AL, Bonomo R, Gautron L, Lee S, Mansuy-Aubert V. Liver $X$ receptors protect dorsal root ganglia from obesity-induced endoplasmic reticulum stress and mechanical allodynia. Cell Rep. 2018;25:271-277 e4.

\section{Publisher's Note}

Springer Nature remains neutral with regard to jurisdictional claims in published maps and institutional affiliations.

\section{Ready to submit your research? Choose BMC and benefit from:}

- fast, convenient online submission

- thorough peer review by experienced researchers in your field

- rapid publication on acceptance

- support for research data, including large and complex data types

- gold Open Access which fosters wider collaboration and increased citations

- maximum visibility for your research: over $100 \mathrm{M}$ website views per year

At $\mathrm{BMC}$, research is always in progress.

Learn more biomedcentral.com/submission 